\title{
The Language of Music as a Specific Semiotic Structure
}

\author{
Tatiana Vladimirovna Lazutina ${ }^{1} \&$ Nicolay Konstantinovich Lazutin ${ }^{1}$ \\ ${ }^{1}$ Tyumen State Oil and Gas University, Russian Federation \\ Correspondence: Tatiana Vladimirovna Lazutina, Tyumen State Oil and Gas University, Volodarskogo Street, \\ 38, Tyumen, 625000, Russian Federation.
}

$\begin{array}{lc}\text { Received: November 1, } 2014 & \text { Accepted: December 23, } 2014 \quad \text { Online Published: March 16, } 2015 \\ \text { doi:10.5539/ass.v11n7p201 } & \text { URL: http://dx.doi.org/10.5539/ass.v11n7p201 }\end{array}$

\begin{abstract}
This work has appeared due to the interest to the semiotic problems of musical art and wish to understand the nature of music and its language as a specific type of creating symbols. Within the framework of semiotics of the culture the article analyses the semiotic system (from the simplest signals to more complicated systems symbols) which function in music. The concept of investigation is determined by the understanding of music language as a specific artificial language which uses diverse symbolic formations for transferring specific information. The central problem of the work was to reveal the nature of music language existence as a complicated semiotic structure. The investigation of the specific nature of music existence which uses the developed system of axiological orientations is not only of theoretical interest but is also of great applied significance. The studying of the music language problem allows to investigate questions connected with the search of the specific nature of semiotic formations used in the art; this pushes forward the development of both general and musical semiotics.
\end{abstract}

Keywords: creating symbols, symbol, language, imaging system, the traditional art and culture

\section{Introduction}

The central point of investigation is music as a sociocultural phenomenon. The studying of semiotic problems of culture is very acute since the investigation of culture is not only of theoretical interest (within the framework of philosophic epistemics, social science, esthetics, semiotics etc.) but it also comprises one of the most important tasks of modern scientific practice (Kim, 2008). The development of musical semiotics is of great applied significance; it is proved by a lot of scientific developments, made by modern investigators of cultural phenomena (Bakhtizina, 2012; Kreidlin, 2004) since the understanding of music language as a specific semiotic system can lead to the enhancement of terminological mechanism of cultural and music philosophy.

This work has appeared due to the interest to the music nature and music language as a symbols creating process (Lazutina, 2013; Bonfeld, 2006). Due to this fact the central point of the investigation is the language of music as a sociocultural phenomenon.

\section{Methods}

The goal of the work is the analysis of the specific nature of the music language. This was made by means of using the material on musical culture history of different genres. The problem statement, studying in this article, is the analysis of symbolic nature of music language. This became the result of analysis of culturological material (Bonfeld, 2006) and generalisation of scientific (Langer, 2006), semiotic (Eco, 2006) and philosophic knowledge; that's why the leading method of organisation is the systematic approach.

This work uses the achievements of the Russian and foreign authors in the sphere of culture semiotics (Borev, 2005; Kudryashov, 2006), ontology and cognitive theory (Goncharov, 2006), as well as philosophic anthropology (Berger, 1997; Bart, 2001). During the investigation of symbols creating in music we used dialectical method, which contribute to study the whole and diverse features of an object, as well as semiotic analysis and systematic approach which allow to consider the music language as a wholeness, open for changes.

\section{Results}

The problem of language as a specific cultural system is the core problem of the modern philosophy (Koopman, 2014); here one can see the increase of interest to the music philosophy (Kholopova, 2014) within the framework of which the music language is considered as a specific information system which, being dynamical, express the 
system of human (society) world outlook concepts. The peculiarity of the art is the formation of the reality image by means of language system.

In the process of music phenomena study we drew the conclusion of the fact that the music is an art which captures the world image by means of the developed system of a specific language system which is able to reflect and model phenomena, emotions and reproduce the peculiarities of their real structure.

The significance of this work is conditioned by its scientific novelty and comprises in interdisciplinary analysis of the music language. The philosophic concept of music language overcomes the imperfections of its specialized investigations, deepens the understanding of its specific nature, determines the prospects of its further study and implementation.

Theoretical significance of the investigation comprises in the fact that it has the concept of music existence, which was developed on the basis of analysis of language music genesis and revealing of prospects of its development; this concept develops the philosophic ontology and cognitive theory.

By means of creating an abstract model as some ideal-mental correlate of the symbolization process in the music we discovered the mechanisms of turning a musical image into symbol which can be used as a methodological basis while studying problems connected with the philosophic foundations of cognition and artistic creation.

The practical implications of the investigation comprises in the fact that its results allow us to reveal the peculiarities of different semiotic structures interaction mechanisms as well as their influence on a human (on the example of music). The reconstruction of the music language genesis allows us to prove the necessity of national and authentic development of music culture in the modern society which choice provides the maximum demand for the spirituality.

\section{Discussions}

The problem of language as a special culture system is the core issue of the modern philosophy and semiotics. Nowadays semiotics plays an important role in the methodology of the humanities. The semiotics considers any cultural phenomena as symbolic formations which have symbolic mechanisms of fixation. The foreign philosophy of art, in particular in works by U. Eco, the reading of works is considered as a continuous oscillating process, where "one transfers from the work itself to the initial codes hidden in it, and basing on these codes one transfers further to more correct reading of the work and then again to the codes, but those of our era, and from these codes - to the continuous comparison and opposition of different interpretations" (Eco, p. 113). Due to this fact a special attention of investigators is paid to the cultural semiotics which considers the culture as a hierarchy of semiotic structures, as a hierarchy which has its own logic of development that is fixed in semiotic practices. Basing on the above said we can form an opinion according to which the problem of language as a cultural system is a central problem not only for the language science but also for the complementary sciences. Thus, the music language is of great interest from the viewpoint of its existence and is considered within the framework of music philosophy as a specific system which, being dynamical one, can for a developed concept of being for human.

The addressing of the music language to the outer world and to the world of human determines a special interest of academic pursuits in the sphere of modern language science in which one can point out the duality of the musical art nature, which in its turn defines the complicated nature of its analysing. The music language is a system having natural and cultural origins in equal measures, here the physiological exists upsides with the psychic and the social, the emotional "lives" together with the rational etc.

The art is a product of cultural activity of people, the image of which is the surrounding world (objective reality), the world of human emotions, feelings, experiences and affections, spheres of thinking, captured by the developed semiotic structure (subjective reality), i.e. the art is of imagery nature and the images which function in the art, reproduce aesthetic qualities of the subjective and objective reality with the help of specific means of expression (pictorialism).

The peculiarity of the art is the formation of the reality image by means of the developed language system. The music language can metaphorically reflect and model phenomena, emotions as well as reproduce peculiarities of their actual structure. Music is an art which captures the world images by means of the developed system of the specific language which transfers a specific artistic image, being a specific "end" of the artistic activity of an artist (composer, poet, stage director etc.) and is considered as an individualized generalization of something typical in art (as the general always reveals in the individual). Music reflects the phenomena of the real world as well as the process taking place in the human psyche. The logical-intuitive, the rational and the sensual, the conscious-unconscious in the music image are in different proportion. 
The music image is determined in this work as a type of an artistic image which reproduces aesthetic qualities of the subjective and objective reality with the help of musical sounds; as a complicated hierarchical system which is understood by means of music language which is a unique means of transferring aesthetic information.

Musical image exists (and is creating) through the system of musical signs (symbols). The whole musical image in the process functioning turns into the musical symbol ("macro-symbol") which in its turn can be represented as a sum of two or more symbols ("micro-symbols"). Music piece comprises of the elements ("micro-symbols") which get the definite meaningful sign (potential "macro-symbol") across to the listeners. Musical image and symbol as the categories of musical art are universal.

Musical symbol is a sign having a figurative (second) meaning which is characterized by the general meaning; the universal category of the music art which is functioning on all the levels of music system organisations.

The symbol in music is used on individual, inter-group, social and generation levels. Music can turn individual sensual data into symbols. While perceiving musical phenomenon all the signals, addressed to a listener, are processed and turned into signs which then can evolve into symbols. Sometimes a composer prefer to use one and the same signs (symbols), that's why it is possible to speak of the author signs (symbols), the symbols of the author style. For example, famous major scale which ends the minor prelude or fugue by J. S. Bach. The analysis of psycho-physiological aspects of musical art showed that the music is an ideally-virtual reality.

The investigators of the modern music science are interested in the questions of musical phenomena existence and analysis of specific musical information and musical image. By means of the specific language music penetrates into all spheres of human life and activity, its language is a universal means of recording, keeping and transferring of specific signals among different generations of people.

In the course of investigation we stated that music is a special information, and the musical art can express (depict) the world of emotions, feelings, experiences of a person, having a diverse and deep interpretation of the coded meanings with the help of complicated sign system. In this work under the sign we understand an object which replaces the other object and which serves for acquiring, keeping and transferring information.

The information which is transferred by the music language is polysemic as there is no fixed connection between the signified and the signifying. This allows us to speak of the music language as a universal means of communication.

Due to the complexity of this phenomenon there are different approaches to its study. Following the principles of historicism allows us to observe the interconnection of the aesthetic attitude of a person and the social practice.

A special significance belongs to the principle of the consistency in studying music language as it orients us to the revealing of the wholeness of the artistic phenomena, shows the role of an individual element in the structure of the whole.

The language of music is a multifunctional phenomenon which performs the following functions: social function which is to form social ideal (Adorno, 2008; Denisova, 2000); cognitive function which allows creating the axiological worldview; cultural-educational function which consists in formation of cultural thinking; educational-pedagogic function (Broun, 1999); humanistic function which is necessary for proper understanding of axiological baselines; methodological function which implements the possibility of using philosophic methods in order to implement axiological orientations.

The society needs to develop music culture as an effective means of crisis overcoming, which from time to time occurs in the spiritual life by means of the integrated system of methods of educating music skills. Music philosophy as a specific form of social conscious forms the worldview of a person. Something that sounds musically stimulates the formation of the developed worldview and expresses pro-active attitude of a social subject.

Music is a form of development, a way of axiological relations existence, it is considered as a sum of material and spiritual values which were created by a person, the aim of this form is the creation and transferring of the diverse world of values by means of a specific language, formation of the social ideal; all these is implemented in social-axiological function. Values which are functioning in music are mutually conditioned, they are individualized and generally significant, they are historical and beyond history, regional and global, one can apply a dialectical approach to them which allows to form a developed notion of them. In the music language the individual and the social are combined to the greater extend than in other art forms.

The analysis of the empiric material of music allows us to state that the aim of the music art is the transfer of aesthetic relations of a person to something that happens in reality, showing of its different experiences, but not 
copying them. The music language can not only depict phenomena and objects of the surrounding world but can also convincingly show fantastic, irrational objects and abstract notions in the form music images. The imaging in music became possible due to the evaluative function of the music language.

Music language not only transmits musical images but also unites different generations of people being a generation memory of the humanity. This means that we speak of the ideologically-uniting function. Musical culture plays the leading role in the uniting ethnic groups by means of the specific language of symbols.

Music performs heuristic-cognitive function since it is a means of forming and expressing thoughts. With the help of the music language the cognition and self-cognition become possible, it keeps cognitive experience of generations which live in different historical eras. Nominative function of the music language which allows to point out the object of investigation from the cognitive situation, is closely connected to the representational function which make it possible to present the results of the cognitive activity as well as with the significative function which implements generalisation, abstraction and explanation.

The ideas of the humanistic function of the art, including musical one, first appeared not in the music science but in philosophy: in the ancient times it was studied by Pythagoreans, Democritus, Plato, Aristotle, then it was considered in the works of Augustine of Hippo, Peter Abelard, within the framework of the Modern age philosophy (R. Descartes, F. Bacon, G. Leibniz) in classical German philosophy (I. Kant, G. W. F. Hegel) and other philosophic schools, but even now it remains acute. No doubt that the music performs humanistic function, and the addressing to the music art is favourable as it allows developing of that something in a person which makes him/her as he/she is, taking a person from the world of nature.

No doubt that music (especially academic) contributes to the formation of the whole worldview, it harmonizes the relations between the world and a person, helping the establishment of the developed personality since the harmony elevates human spirit. Something that sounds musically contributes to the formation of the developed worldview, actively expresses the status of the social subject.

Among the functions of music language we can point out the main and derivative ones. The main (general) function of the cultural language is informative-communicational function (Lazutina, 2013).

By means of the specific language music functions in all spheres of human life and activity, its language is a universal means of recording, keeping and transferring of specific signals among different generations of people. Music language is a specific semiotic structure which serves for transferring aesthetic information. Despite the fact that each art language has a specific nature which influences the position of this art in the hierarchy of cultural values of this or that era, but according to the modern culturological investigations the language of any art itself is subjected to the evaluation (otherwise it could result in the situation in which it is possible to speak of the fact that the language of drama is "better" than the language of opera or ballet). Nevertheless it is reasonable to say that the language of music is one of the universal means of compressing and preserving information, it forms its uniqueness. We can say that the music is the most communicative (among other art forms) art of sounds, which exist in society and penetrate in the life of a person on the maximum level.

Language of music is a complicated hierarchical and constantly renewing semiotic system on the levels of which there exist different systems of signs creation, where any individual sign is included in a definite semiotic system.

Semiotic system of the music language, as any system, consists of elements. The elements of music language as a specific semiotic structure are sounds (tones). We can state that the physical nature of music is sound-temporal.

Though music is a formation which combines musical and extramusical spheres where the so-called "extramusical" contains intonations of human speech (including different interjections, cries, laughter etc.), the distinctive feature of music as art is the reflection of the reality in the form of images, that influence the perception and are implemented in musical sounds (tones) (Lazutina, 2013).

Let us make an assumption that any sound can be musical if the following conditions are met: use in musical message; complex perception of sound qualities while revealing main feature of sounding; considering sound in combination with other sounds of music in conjunction with them (mode) as music is art which operates with different sounds (Lazutina, 2015).

Music has both pitch-definable sounds (tones) and undefinable (noises) which has some specific features (Aldoshyna, 2009), which acquire special meaning in the process of functioning in the musical art. Consequently, it is a mistake to think that the accuracy of sound pitch fixation is a marker of its belonging to music. 
So, the music is the art of tones and its specific feature is the fact that it reflects the phenomena of the surrounding world in the form of images which, influencing the perception, are implemented by means of musical sounds (tones).

The characteristic feature of the language of music is the presence of different semiotic levels (sound-pitch, rhythmic, compositional, performing levels) (Lazutina, 2013).

The elements of the music language are interconnected, one an the same element can mutually penetrate the other, for example, an individual sound enters the music theme, the theme in its turn can serve as an impulse which takes part in the development of the form being on the higher hierarchic level (Zaderatskiy, 2008).

In the process of language music functioning which includes the process of composing, performing and perception of music phenomena, its elements are endued with symbolic meaning. The so-called symbolization is taking place.

Symbolization in music is a process of enduing of musical phenomena with the transferred meaning. The process of symbolization is based on the preservation of traditions, being supported by the standardised rhythm-formulas in the sphere of rhythmic organisation of music and melodic, harmonic forms which has canonic features. These features exist on the sound-pitch level of the music system together with the correlation with improvisation of symbol creating (Lazutina, 2015).

Today the opinion that the language of art is the language of symbols is quite convincing. The symbol reveals the abundance of the meaningful world of music, being such a class of symbol creating which is the most difficult to define and organise.

The symbols in music can be both separate sounds, their melodic, harmonic, timbre and dynamic combinations as strictly differentiated musical images which carried by means of definite music composition, organisation, genre, author style.

The use of semiotic approach to the music art is promising as it allows to see a communicative system in music; this system has specific content and abilities to transfer the image of the world in the conscious by meas of musical images. A special question of musical semiotics is represented by the signs typology.

Musical symbolics is implemented on different levels of music system. In the process of cognition of the objective reality the conscious of the subject builds symbolic images which allow speaking of symbols which function on individual level together with which there is used symbolics which exists on general human level. We can suppose that music art is represented by the symbolics of different types: individual and synthetic symbols.

Music also uses symbols of expression and depiction. The symbols of expression are: symbolic reflection of the inner world of human (human conscious), which in its turn is nominally divided into emotional and rational symbolics. Emotional side of music is revealed by the so-called psychological symbolics which includes symbols of emotions, feelings, perceptions and experiences, and religious symbolic. Rational-logical side of music helps to understand the complex of the so-called philosophic, ethic and aesthetic symbols.

The symbols of depiction are sign formations which reflect objects and phenomena of the surrounding world symbols of the nature (environment of Water, Earth, Air and Fire; flora and fauna), symbols which transfer the peculiarities of the outer (real) world of human (peculiarities of appearance: intonations, gestures, walk, facial gestures) as well as the symbols of the world created by a human (the sphere of human activity, world of science and art).

The symbol in music can be divided into the following classes:

\section{1. the symbols of natural languages}

2. according to the method of reality reflection the music symbols can be depictive (symbols of imitation of qualities, features of phenomena and objects, symbols of coding of the outer form, perspective, space, depth)

3. intelligible (theoretic)

4. rational-logic (symbols of abstract notions, phenomena, philosophic categories)

5. real objects
1. the symbols of artificial languages

2. expressive (complex of psychological symbols: symbols of experiences, emotions, feelings, perceptions, moods)

\section{3. sensible (sense-perceived)}

4. emotional (symbols of feelings, experiences)

5. irreal objects (fantastic creatures, objects, events) 
Applying the typology of sign developed by Yu. Borev (2005) to the art of music it is offered to differentiate the following types of musical signs (according to the character and goals of functioning):

$$
\begin{aligned}
& \text { types of musical signs } \\
& \text { symbols of belonging to } \\
& \text { the culture } \\
& \text { symbols of era } \\
& \text { symbols of national } \\
& \text { character } \\
& \text { symbols of reception } \\
& \text { anticipation }
\end{aligned}
$$

functional symbols

$$
\text { functions of the musical signs }
$$

which emphasize the artificial origin of the work

$$
\text { which function is to carry the information of the national tradition }
$$

a listener's desire to accept music, information about the character, content of the piece (here the role of the prelude in the "small cycle", including the prelude and fugue by I. S. Bach is demonstrative; ouvertures before the opera)

which notifies the purpose of the piece (rhythm serves the functional sign when the character of music corresponds to its purpose), which regulates the behaviour of human.

\section{Conclusions}

Thus the music language is a product of the symbolic activity of people. Musical image is a type of artistic image which reproduce aesthetic qualities of subjective and objective reality with the help of musical sounds.

The logical-intuitive, the rational and the sensual, the conscious-unconscious are in different proportion in the musical image.

Musical image has different degree of the objective and the subjective, expressiveness and pictorialism. It is a means of capture of the complex system of human experiences (empiric moment in cognition - the process of understanding the surrounding world by a person and one's place in it) and thoughts (rational aspect in cognition).

Music is a specific language which performs different functions. Being a phenomenon with a complex organisation the language of music is characterised by multi-functionality. Just as in the sphere of scientific activity, cognitive functions of music language in the sphere of art falls apart into the range of independent individual functions.

Functions of the language music as a special type of system are information-communicative, semiotic, aesthetic, nominative, representational, significative, heuristic-cognitive, social-axiological, evaluative and regulatory-educational etc.

Language music is a special system of musical signs (symbols) which was built in the process of historical development and is universal.

Music language is an informational-communicative system with a complicated organisation. Musical information is rendered by means of music language; this information is understood as a system of images which is rendered by means of expressive (pictorial) means of music art with the help of complicated system of signs having peculiarities on such stages of musical activity as creation, perception and influence of musical phenomena.

Music language is a special self-adjusting system which consists of the sound-pitch, rhythmic, compositional and performing levels where different signals, signs and symbols are functioning.

On each level of music language there is different system of musical signs (from simple ones - signals - to those with complex organisation - symbols).

Music is a type of symbol creating. One of the important aspects of dialectic process of musical image transferring into the symbol is the transfer of information from one level of the language system to the other level of the other language.

Musical symbol is a sign with a transferred (second) meaning which is characterised by the general significance, it is the main material for the music art.

\section{References}

Adorno, T. (2008). Selected works: Music sociology. Moscow М.: Российская политическая энциклопедия.

Aldoshyna, I. (2009). Musical acoustics. St. Petersburg: Composer. 
Bakhtizina, D. I., \& Lukyanova, A. V. (2013). Transcendental sense of classical musuc and the problem of its rootedness in the existence. World Applied Sciences Journal, 24(8), 1006-1008. http://dx.doi.org/ 10.5829/idosi.wasj.2013.24.08.13246

Bart, R. (2001). Semiotics: Anthology (2nd ed.). Moscow: Academic project; Ekaterinburg: Delovaya kniga.

Berger, L. G. (1997). Epistomology of art. Moscow: Russkiy mir.

Bonfeld, M. Sh. (2006). Music: Language. Speech. Thinking. Experience of the systematic investigation of the music art. St. Petersburg: Composer.

Borev, Y. В. (2005). Aesthetic. Moscow: Русь-Олтмп.

Denisova, A. B. (2000). Existence of musical image: ontology-epistemological analysis (PhD thesis). Kazan.

Eco, U. (2006). Absent structure. Introduction into semiology. St. Petersburg: Symposium.

Goncharov, S. Z. (2006). Logic of thinking and axiology of a heart (Ros. Philos. Ekaterinburg: Cultural information ban.

Kholopova, V. N. (2014). Music as a form of art. St. Petersburg: Lan.

Kim, V. V. (2008). Semiotics and scientific cognition: Philosophic-methodological analysis. Ekaterinburg: Ural University publishing house.

Koopman, K. (2007). Community music as music education: on the educational potential of community music. International Journal of Music education, 25(2), 151-163.

Kreidlin, G. (2004). Non-verbal semiotics: Body language and natural language. Moscow: Novoe nauchnoe obozrenie.

Kudryashov, A. Y. (2006). Theory of music content. Artistic ideas of XVII - XX centuries. St. Petersburg: Lan.

Langer, S. (2000). New philosophy: Investigation of the mind, ritual and art symbolic. Moscow: Republic.

Lazutina, T. V. (2013). Music language as a poly-functional phenomenon. Tomsk: Tomsk State University Messanger, 369, 60-63.

Lazutina, T. V. (2015). Music language (2nd ed.). Moscow: Flinta.

Zaderatskiy, V. V. (2008). Music form (Issue 1). Moscow: Music.

Broun, A. R. (1999). Music, media and making: humanising digital media music education. International Journal of Music education, 33(1), 10-17.

\section{Copyrights}

Copyright for this article is retained by the author(s), with first publication rights granted to the journal.

This is an open-access article distributed under the terms and conditions of the Creative Commons Attribution license (http://creativecommons.org/licenses/by/3.0/). 